\title{
Strategies for Reducing Secondary or Vicarious Trauma: Do They Work?
}

\author{
Ted Bober and Cheryl Regehr
}

Version Published Version/Final PDF

Citation Bober, T., \& Regehr, C. (2006). Strategies for Reducing Secondary or

(published version) Vicarious Trauma: Do They Work? Brief Treatment and Crisis

Intervention, 6(1), 1-9. doi:10.1093/brief-treatment/mhj001

Copyright/Licence CC BY-NC-ND

How to cite TSpace items

Always cite the published version, so the author(s) will receive recognition through services that track citation counts, e.g. Scopus. If you need to cite the page number of the author manuscript from TSpace because you cannot access the published version, then cite the TSpace version in addition to the published version using the permanent URI (handle) found on the record page.

This article was made openly accessible by $U$ of $T$ Faculty. Please tell us how this access benefits you. Your story matters. 


\title{
Strategies for Reducing Secondary or Vicarious Trauma: Do They Work?
}

\author{
Ted Bober, MSW \\ Cheryl Regehr, PhD
}

\begin{abstract}
This cross-sectional design study sought to assess whether therapists believed and engaged in commonly recommended forms of prevention for secondary and vicarious trauma and whether engaging in these activities resulted in lower levels of distress. In this study of 259 therapists, time spent with counseling trauma victims was the best predictor of trauma scores. Although participants generally believed in the usefulness of recommended coping strategies including leisure activities, self-care activities and supervision, these beliefs did not translate into time devoted to engaging in the activities. Most importantly, there was no association between time devoted to coping strategies and traumatic stress scores. Intervention strategies for trauma counselors that focus on education of therapists and augmenting coping skills unduly individualize the problem. [Brief Treatment and Crisis Intervention 6:1-9 (2006)]
\end{abstract}

KEY WORDS: secondary traumatic stress, vicarious trauma, coping, self-care, supervision.

Attention to the impact on individuals of exposure to catastrophic or life-threatening events over the past 30 years has resulted in new treatment methodologies and approaches aimed at reducing posttraumatic distress symptoms in the sufferers. Mental health workers are providing services increasingly focused on traumatic memory and traumatic symptomatology. Because of the realization that this focus does not come without cost to the individual therapist, a newer literature focuses on the costs of caring for therapists themselves. Terms used

From Ontario Medical Association (Bober) and the University of Toronto (Regehr).

Contact author: Cheryl Regehr, Professor, Faculty of Social Work \& Faculty of Law, Sandra Rotman Chair in Social Work Practice, Director, Centre for Applied Social Research, University of Toronto, 246 Bloor Street West, Toronto, Ontario M5S 1A1, Canada. E-mail: cheryl.regehr@ utoronto.ca

doi:10.1093/brief-treatment/mhj001

Advance Access publication December 30, 2005 to describe this phenomenon are varied, but the most common include secondary traumatic stress and vicarious trauma. Although there is overlap between the concepts underlying these terms, there are also differences. Secondary trauma or secondary traumatic stress refers to a set of symptoms that parallel those of posttraumatic stress disorder (PTSD) or acute stress disorder as defined in the Diagnostic and Statistical Manual of the American Psychiatric Association (APA, 2004). Vicarious trauma focuses on the cognitive schemas or core beliefs of the therapist and the way in which these may change as a result of empathic engagement with the client and exposure to the traumatic imagery presented by clients. This may cause a disruption in the therapist's view of self, others, and the world in general (McCann \& Pearlman, 1990; Sabin-Farrell \& Turpin, 2003). Although these distinctions in the literature

(c) The Author 2005. Published by Oxford University Press. All rights reserved. For permissions, please e-mail: journals.permissions@oxfordjournals.org. 
may lead to alternative tools to measure the phenomenon, it is increasingly understood that there is convergence between these two concepts (Jenkins \& Baird, 2002), and therapists working with trauma victims experience disruptions in both realms (Pearlman \& MacIan, 1995). Consequently, articles and books in the scholarly and professional literature seek to understand and explain these experiences and determine means for reducing distress among trauma therapists.

Several quantitative studies point to elevated rates in trauma among counselors and therapists working with traumatized individuals, nevertheless, whereas these studies support the notion that trauma counselors endorse items on questionnaires consistent with secondary traumatic stress and vicarious trauma, symptoms generally do not reach a clinically significant level or one in which symptoms markedly interfered with functioning (Arvay \& Uhlemann, 1996; Brady, Guy, Poelstra, \& Brokaw, 1999; Chrestman, 1995; Kassam-Adams, 1995; Ortlepp \& Friedman, 2002; Schauben \& Frazier, 1995). For instance, a study of 70 human rights workers in Kosovo who were responsible for collecting data on human rights violations revealed elevated levels of anxiety in $17.1 \%$, depression in $8.6 \%$, and PTSD symptoms in $7.1 \%$ (Holtz, Salama, Cardoza, \& Gotway, 2002). Among lay trauma counselors who had been trained to assist bank employees following bank robberies in South Africa, 10\% reported secondary traumatic stress symptoms in the high or extremely high range (Ortlepp \& Friedman, 2002). Conversely, in a study of 173 child welfare workers exposed both to traumatic imagery through the stories of clients and direct exposure to trauma such as violence and threats directed at them, $46.7 \%$ reported traumatic stress symptoms in the severe range (Regehr, Chau, Leslie, \& Howe, 2002a, 2002b).

Qualitative studies and anecdotal reports have described the experiences of trauma thera- pists in more detail. Similar to traumatic stress, symptoms of vicarious trauma can include immediate reactions such as intrusive imagery, nightmares, increased fears for the safety of oneself and loved ones, avoidance of violent stimuli in the media, difficulty listening to clients' accounts of events, irritability, and emotional numbing. Longer term reactions can include emotional and physical depletion, a sense of hopelessness, and a changed world view in which others are viewed with suspicion and cynicism (Iliffe \& Steed, 2000; Ortlepp \& Friedman, 2002; Regehr \& Cadell, 1999; Schauben \& Frazier, 1995).

Factors that influence symptom level include the number or percentage of trauma cases on a therapist's caseload (Brady et al., 1999; KassamAdams, 1995; Marmar et al., 1999; Ortlepp \& Friedman, 2002; Resnick, Kilpatrick, Best, \& Kramer, 1992; Schauben \& Frazier, 1995), the availability of social support (Ortlepp \& Friedman, 2002; Schauben \& Frazier, 1995), personal histories of trauma and abuse (Jenkins \& Baird, 2002; Kassam-Adams, 1995; Pearlman \& MacIan, 1995; Wall, 2001), and the perception that they had adequate training to effectively assist victims, thereby reducing the sense of hopelessness that may accompany this work (Ortlepp \& Friedman, 2002).

Theorists in the area of secondary or vicarious trauma recommend a variety of strategies for reducing levels of symptoms and disruption. Several authors point to the importance of maintaining a balance between work and personal life (Figley, 1995; Hesse, 2002; Pearlman \& Saakvitne, 1995; Regehr \& Cadell, 1999). Seeking psychotherapeutic treatment to assist with countertransference issues related to unresolved events in ones' personal history and secondary trauma are recommended (Hesse, 2002; Pearlman \& Saakvitne, 1995; Sexton, 1999; Yassen, 1995). Peer consultation, supervision, and professional training to reduce the sense of isolation and increase feelings of 
TABLE 1. Strategies Recommended in the Literature for Reducing Secondary or Vicarious Trauma

Seeking psychotherapeutic treatment Peer consultation

Supervision

Professional training

Reducing number of trauma cases on caseload Self-care

efficacy are suggested (Cerney, 1995; Dane, 2000; Pearlman \& Saakvitne, 1995; Talbot, 1989). Finally, stemming from the association between exposure and symptoms, reducing the number of trauma cases is frequently suggested (Hesse, 2002; Pearlman \& Saakvitne, 1995). These strategies are mirrored by therapists participating in qualitative studies and in anecdotal reports by therapists whose suggestions include peer support, physical activity and self-care, reading and watching TV shows or movies that are nonviolent, limiting their trauma counseling workload, and political activism (Astin, 1997; Iliffe \& Steed, 2000) (Table 1).

What remains unclear, however, is whether these strategies are in fact effective in avoiding vicarious or secondary trauma or in reducing trauma symptoms when they occur. This study seeks to assess whether therapists believe in commonly recommended forms of prevention, whether they engage in the activities recommended, and finally whether engaging in these activities results in lower levels of distress.

\section{Method}

This research utilized the self-report questionnaire format. Clinical programs that specialized in work with victims of violence in southern Ontario were identified, and questionnaires were distributed with self-addressed envelopes to therapists in team meetings or by mail. Of the total 580 questionnaires that were distributed, 259 were returned, resulting in a return rate of $45 \%$. Social workers comprised $47.7 \%$ of the sample. Of the remaining, $15.5 \%$ identified nursing as their primary profession, $13.6 \%$ psychology, $10 \%$ physician, and fewer than $13 \%$ reported that they were from each of a variety of disciplines and included child and youth worker, occupational therapists, and chaplain. In all, 209 (80.7\%) participants were women. The mean age of participants was 41.31 $(S D=9.29)$ years. Participants indicated that they had worked a mean of 10.17 ( $S D=$ 6.59) years as a counselor or therapist and worked an average of $16.32(S D=10.88)$ hours per week in counseling and $8.36(S D=8.35)$ hours per week counseling traumatized individuals. Seventy-nine individuals in this sample indicated that they had roles as managers and clinical supervisors in addition to identifying themselves as counselors. Of these, 55 participants indicated that they were managers, 58 clinical supervisors, and 29 participants indicated that they carried both roles (Table 2).

\section{Measures}

Demographic variables were collected via a questionnaire that covered age, gender, education, years in counseling, hours per week of trauma counseling, and types of trauma victims treated.

The Impact of Event Scale(IES; Zilberg, Weiss, \& Horowitz, 1982) was used to assess symptoms related to posttraumatic stress. It extracts dimensions that parallel the defining characteristics of the $D S M-I V$ criteria for PTSD, which are signs and symptoms of intrusive cognitions and affects together or oscillating with periods of avoidance, denial, or blocking of thoughts and images. This scale is reported to have high internal consistency with a Cronbach's alpha of 0.86 and a test-retest reliability of 0.87 . 


\begin{tabular}{ll}
\hline TABLE 2. Characteristics of the Sample $(N=259)$ \\
Age & 41.31 years \\
& $(S D=9.30)$ \\
Gender & \\
Female & $80.7 \%$ \\
Male & $19.3 \%$ \\
Education & \\
Some college & $15.5 \%$ \\
Bachelor's degree & $18.6 \%$ \\
Master's degree & $51.2 \%$ \\
Doctorate & $13.2 \%$ \\
Profession & \\
Social work & $47.7 \%$ \\
Nursing & $15.5 \%$ \\
Psychology & $13.6 \%$ \\
Medicine & $10.0 \%$ \\
Other & $13.0 \%$ \\
Counseling experience & \\
Years as a counselor or therapist & 10.17 \\
& $(S D=6.59)$ \\
Hours per week doing counseling & 16.32 \\
Hours per week counseling & $(S D=10.88)$ \\
trauma victims & 8.36 \\
\hline & $(S D=8.35)$ \\
\hline
\end{tabular}

This instrument is one of the most commonly used ones in research related to secondary or vicarious trauma (Sabin-Farrell \& Turpin, 2003).

The Traumatic Stress Institute (TSI) Belief scale was used to assess vicarious trauma symptoms in a subsample of participants (Pearlman, 1996). This 80 item scale has 10 subscales (1) self-safety (the belief that one is secure and safe from harm); (2) other-safety; (3) selfesteem; (4) other-esteem (the belief that others are valuable); (5) self-trust (belief in one's own judgments); (6) other-trust; (7) self-intimacy (connection to self); (8) other-intimacy (connection to others); (9) self-control; and (10) other-control. Reported reliability coefficients for subscales range from 0.62 to 0.91 (Jenkins \& Baird, 2002; Pearlman \& MacIan, 1995).

The Coping Strategies Inventory (CSI; Bober, Regehr \& Zhou, 2006) is composed of two sec- tions: (a) beliefs that trauma therapists hold regarding which coping strategies will lead to lower levels of secondary trauma and (b) time available for engaging in coping strategies. The instrument was tested on samples of 259 therapists and 71 hospital workers who did not provide counseling services. The CSI-Belief (CSI-B) scale has three subscales: leisure, selfcare, and supervision, which have reported internal reliability coefficients of $0.71-0.82$. The CSI-Time (CSI-T) scale has four subscales: leisure, self-care, supervision, and research and development have reported internal reliability coefficients of $0.67-0.80$.

\section{Results}

\section{Factors associated with levels of secondary and vicarious trauma}

Age of therapists was negatively associated with IES total scores $(r=-.14, p \leq .05)$, and this difference was accounted for by differences in avoidance subscale scores $(r=-.18, p \leq .01)$. The total hours per week spent providing counseling services was significantly associated with IES scores $(r=.25, p \leq .001)$ and in particular intrusion symptoms $(r=.32, p \leq .001)$. Further, the hours per week spent counseling traumatized individuals was more highly correlated with IES total $(r=.31, p \leq .001)$, avoidance $(r=.24, p \leq .001)$, and intrusion $(r=.34$, $p \leq .001)$ scores. That is, those who were older had lower levels of distress, and those who spent more time counseling had higher levels of distress. There was no significant difference in trauma scores between supervisors and managers and other counseling staff.

IES scores differed with type of traumatized clients to which counselors were exposed. Those counselors working with workplace trauma, victims of violent crime, and unexpected death had equivalent mean scores on 
TABLE 3. Factors Associated with Levels of Vicarious or Secondary Trauma

\begin{tabular}{|c|c|c|c|}
\hline Variable & IES Intrusion & IES Avoidance & IES Total \\
\hline Age & $r=-.06$ & $r=-.18^{\star \star}$ & $r=-.14^{*}$ \\
\hline Total hours per week counseling & $r=.32^{\star \star}$ & $r=.15^{\star}$ & $r=.25^{\star *}$ \\
\hline Hours per week counseling trauma victims & $r=.34^{* *}$ & $r=.24^{\star \star}$ & $r=.31^{\star *}$ \\
\hline Counseling wife assault victims & $t=-3.11^{* *}$ & $t=-2.31^{* *}$ & $t=-2.92^{\star *}$ \\
\hline Counseling child abuse victims & $t=-2.92^{* *}$ & $t=2.30^{\star *}$ & $t=-.2 .75^{* *}$ \\
\hline Counseling child sexual abuse victims & $t=-3.65^{* *}$ & $t=-3.12^{* *}$ & $t=-3.78^{\star *}$ \\
\hline Counseling sexual assault victims & $t=-3.70^{* *}$ & $t=-1.96^{*}$ & $t=-3.01^{\star *}$ \\
\hline Counseling torture victims & $t=-2.33^{*}$ & $t=-2.57^{* *}$ & $t=-2.62^{* *}$ \\
\hline Receiving personal therapy & $t=-2.15^{*}$ & $t=-2.38^{*}$ & $t=-2.34^{*}$ \\
\hline
\end{tabular}

Note. Scores on the Impact of Event Scale (IES).

${ }^{*} p \leq .05 .{ }^{*} p \leq .01$.

the IES to those who did not. Counselors working in areas of wife assault $(t=-2.92$, $p \leq .001)$, child abuse $(t=-2.75, p \leq .01)$, child sexual abuse $(t=-3.78, p \leq .001)$, sexual violence $(t=-3.01, p \leq .01)$, and torture $(t=-2.62, p \leq .01)$ did have higher scores than their counterparts not serving these populations. Scores on the IES were not significantly associated with whether counselors had personally experienced traumatic events in childhood or adulthood. However, IES scores were significantly associated with receiving personal therapy $(t=-2.34, p \leq .01)$ (Table 3). That is, those who had sought therapy had higher IES scores, they were also significantly more likely to have experienced personal trauma in both adulthood $(\chi=84.42$, $p \leq .001)$ and childhood $(\chi=17.19, p \leq .001)$.

A subsample of 53 participants also completed the TSI Belief scale. There was no association between number of hours per week spent counseling or providing trauma-specific counseling and any of the subscales of the TSI or the TSI total score. Age and years of experience were only correlated with the other-intimacy subscale $(r=.36, p \leq .001$ and $r=.29, p \leq .01$, respectively). That is, older and more experienced people had more maladaptive beliefs regarding intimacy with others. Managers and supervisors had signifi- cantly less maladaptive beliefs about trust of others than did other counselors $(t=2.12$, $p \leq .05)$ and significantly lower overall TSI scores $(t=2.01, p \leq .05)$. Unlike the IES scores in which those dealing with child abuse, torture, and wife assault were more distressed than their counterparts who did not serve these populations, only those counselors dealing with rape had significantly higher TSI total scores than others $(t=2.48, p \leq .05)$ and most significantly had dysfunctional beliefs regarding personal control $(t=1.11, p \leq .01)$. Scores on the TSI were not associated with personal histories of traumatic events in childhood or adulthood. Those receiving treatment had more maladaptive beliefs regarding self-trust $(t=2.06, p \leq$ $.05)$, other-safety $(t=2.49, p \leq .05)$, and self-esteem $(t=2.36, p \leq .05)$.

\section{Coping strategies and vicarious trauma}

CSI-B subscales ask participants to rate a series of activities according to the degree to which they believe that each will assist with dealing with the demands of trauma work on a 5-point scale ( 0 being not at all and 4 being always helpful). The leisure subscale includes five items that obtained mean scores as follows: time with family $3.36(S D=0.75)$, vacation 3.55 $(S D=0.71)$, movies/TV $2.62(S D=1.01)$, 
TABLE 4. Relationship Between Time Spent Engaging in Coping Activities and Trauma Scores

\begin{tabular}{lccc} 
Variable & IES Intrusion & IES Avoidance & IES Total \\
\hline Leisure (time with family, vacation, hobbies, exercise) & $r=-.04$ & $r=-.03$ & $r=-.03$ \\
Self-care (stress management training, self-care plans) & $r=.04$ & $r=-.09$ & $r=-.04$ \\
Supervision (case discussions, regularly supervision) & $r=.06$ & $r=.02$ & $r=.04$ \\
Research and development (educating others, & $r=.05$ & $r=-.02$ & $r=.10$ \\
participating in research, program planning) & & & \\
\hline
\end{tabular}

Note. No significant associations found.

hobbies $3.16(S D=0.80)$, and exercise 3.34 $(S D=0.83)$. Thus, it is clear that participants believed that leisure activity was usually-toalways useful for assisting with the effects of trauma work. Mean scores for the five items in the self-care subscale fell between somewhat helpful and usually helpful $(M=2.69$ and $S D=$ 1.05 for team self-care plans; $M=3.11$ and $S D=0.86$ for individual stress management training). Mean scores for the four items on the supervision subscale were slightly lower but continued to fall between somewhat and usually helpful $(M=2.10$ and $S D=1.06$ for discussing cases with management; $M=3.16$ and $S D=0.67$ for discussing cases with colleagues). Thus, there is a general belief that strategies recommended in the literature are helpful for reducing vicarious trauma. Age, years of counseling, and hours per week spent counseling were not associated with CSI-B scores. However, managers and supervisors were significantly more likely to believe in the benefits of supervision for reducing trauma than other counselors $(t=2.53, p \leq$ .01 ) and not surprisingly were significantly more likely to devote time to engage in it $(t=3.53, p \leq .001)$. There was no difference between supervisor/managers and other counselors on any of the other subscales.

Data analysis attempted to determine the association between scores on the CSI-B and CSI-T subscales. Pearson's correlations revealed no significant associations between beliefs in the benefits of self-care and leisure and time allotted for engaging in these activities. However, those who believed in supervision were significantly more likely to devote time to obtaining supervision $(r=.42, p \leq .001)$. In addition, those who believed in the benefits of selfcare were more likely to engage in supervision $(r=.18, p \leq .01)$ and research and development $(r=.17, p \leq .05)$. Hours per week worked in trauma counseling was not associated with time allotted for any of the domains.

Most central to this inquiry, there was no association between time allotted for engaging in leisure, self-care, supervision, or research and development and levels of trauma symptoms as measured by the IES (Table 4). The total TSI Belief scale score was negatively associated with time available for leisure activities $(r=$ $-.32, p \leq .05)$. That is, those with more maladaptive beliefs had less time for leisure activities. The only correlations between CSI subscales and TSI subscales were that time for self-care activities was negatively correlated with the TSI other-esteem subscale $(r=-.30, p \leq$ $.05)$, and time for leisure was negatively correlated with both self-intimacy and otherintimacy $(r=-.37, p \leq .01$ and $r=-.29$, $p \leq .05$, respectively). There were no associations between TSI Belief subscales and CSI-B subscales (Table 4).

Stepwise multiple regression was used to predict overall severity of posttraumatic stress symptoms on the IES for the counselor group. 
It was required that a variable that lead to an increase in variance accounted for $R^{2}$ of $2 \%$ or more and be significant at the $p \leq .05$ level. Variables in the initial analysis included personal history of trauma, personal therapy, hours per week spent working with traumatized individuals, and the CSI-T subscales. The final equation for the IES, contained only one variable, hours per week working with traumatized individuals, and yielded a multiple $R$ of .27 ( $F=11.46, p=.001)$ accounting for only $7 \%$ of the total variance in posttraumatic stress symptom scores. Due to limited sample size, regression analysis could not be conducted with the TSI.

\section{Discussion}

There is general recognition in the literature and in the field that the intensity of working with traumatized individuals negatively impacts the well-being of therapists. This negative impact includes both immediate effects in terms of symptoms generally associated with posttraumatic stress and longer term effects in terms of altered belief systems. In this study of 259 individuals providing mental health counseling services, those individuals who spent more time per week counseling individuals who were victims of trauma reported higher levels of traumatic stress symptoms as measured by the IES and in particular, higher levels of intrusion symptoms. This finding replicates that of other researchers (Brady et al., 1999; Kassam-Adams, 1995; Marmar et al., 1999; Resnick et al., 1992). Further, confirming the findings of Brady et al. (1999), hours per week counseling trauma victims was not associated with maladaptive cognitive schemas as measured by the TSI Belief scale. However, years of experience was associated with more disruptive beliefs regarding intimacy with others. This suggests that degree of exposure has an impact on intrusion and avoidance symptoms but that altered beliefs do not appear to occur in the short run. Regarding types of exposure, working with victims of interpersonal violence such as wife assault, child abuse, rape, and torture was associated with higher traumatic stress scores, but only working with victims of rape was associated with more disruptive beliefs. Personal histories of childhood or adult trauma were not associated with IES or TSI Belief scores except in individuals who sought treatment, suggesting that those who were distressed and unresolved about personal histories were likely to appropriately seek assistance.

Many coping strategies are recommended by theorists and researchers in the areas of vicarious and secondary trauma, yet to our knowledge no research projects have evaluated the effectiveness of these strategies on reducing distress. In this study, participants generally believed in the usefulness of recommended coping strategies including leisure activities, self-care activities, and supervision, although supervisors were more likely to believe in the value of supervision than frontline workers. However, there was no association between the belief that leisure and self-care were useful and time allotted to engage in these activities. Those who believed in the value of supervision were more likely to devote time to it. Most importantly, there was no association between time devoted to leisure, self-care, research and development, or supervision and traumatic stress scores. Thus, there is no evidence that using recommended coping strategies is protective against symptoms of acute distress. With regard to longer term outcomes, those participants with disrupted belief systems, particularly regarding self-intimacy and otherintimacy, were significantly less likely to engage in leisure activities. With a cross-sectional design it is not possible to determine whether leisure activities are protective against negative 
beliefs regarding intimacy or whether those with less negative beliefs are better able to engage in leisure activities.

In conclusion, it does not appear that engaging in any coping strategy recommended for reducing distress among trauma therapists has an impact on immediate traumatic symptoms. This has important implications for the design and operation of support programs for victims of trauma. As mental health professionals dedicated to the fair and compassionate treatment of victims in society, we have been strong in vocalizing concerns that those who are abused and battered not be blamed for their victimization and their subsequent traumatic response. Yet when addressing the distress of colleagues, we have focused on the use of individual coping strategies, implying that those who feel traumatized may not be balancing life and work adequately and may not be making effective use of leisure, self-care, or supervision. Intervention strategies with therapists have focused on educational seminars, aimed at augmenting individual coping responses. In light of the findings of this study that the primary predictor of trauma scores is hours per week spent working with traumatized people, the solution seems more structural than individual. That is, organizations must determine ways of distributing workload in order to limit the traumatic exposure of any one worker. This may not only serve to reduce the impact of immediate symptoms but may also address the potential longitudinal effects of disrupted beliefs regarding intimacy. It is clear that further research regarding workplace conditions and individual strategies that would prevent, identify, or reduce various and secondary trauma among trauma therapists is urgently needed. Further, it is perhaps time that vicarious and secondary trauma intervention efforts with therapists shift from education to advocacy for improved and safer working conditions.

\section{References}

American Psychiatric Association. (2004). Diagnostic and statistical manual of mental disorders (4th ed., text revision). Washington, DC: Author.

Arvay, M., \& Uhlemann, M. (1996). Counsellor stress and impairment in the field of trauma. The Canadian Journal of Counselling, 30(3), 193-210.

Astin, M. (1997). Trauma therapy: How helping rape victims affects me as a therapist. Women \& Therapy, 20(1), 101-109.

Bober, T., Regehr, C., \& Zhou, R. (2006). Development of the coping strategies inventory for trauma counselors. Journal of Trauma and Loss, 11, 71-83.

Brady, J., Guy, J., Poelstra, P., \& Brokaw, B. (1999). Vicarious traumatization, spirituality, and the treatment of sexual abuse survivors: A national survey of women psychotherapists. Professional Psychology, 30, 386-393.

Cerney, M. (1995). Treating therapists with vicarious traumatization and secondary traumatic stress disorders. In C. Figley (Ed.), Compassion fatigue: Coping with secondary traumatic stress disorder in those who treat the traumatized (pp. 131-149). New York: Brunner/Mazel.

Chrestman, K. R. (1995). Secondary exposure to trauma and self-reported distress among therapists. In B. H. Stamm (Ed.), Secondary traumatic stress: Self-care issues for clinicians, researchers, and educators (pp. 29-36).

Lutherville, MD: The Sidran Press.

Dane, B. (2000). Child welfare workers: An innovative approach for interacting with secondary trauma. Journal of Social Work Education, 36(1), 27-38.

Figley, C. (1995). Compassion fatigue: Towards a new understanding of the costs of caring. In B. Stamm (Ed.), Secondary traumatic stress: Self-care issues for clinicians, researchers, and educators (pp. 3-28). Lutherville, MD: The Sidran Press.

Hesse, A. (2002) Secondary trauma: How working with trauma survivors affects therapists. Clinical Social Work Journal, 30, 293-309. 
Holtz, T., Salama, P., Cordozo, B., \& Gotway, C. (2002). Mental health status of human rights workers, Kosovo, June 2000. Journal of Traumatic Stress, 15, 389-395.

Iliffe, G., \& Steed, L. (2000). Exploring counselor's experience of working with perpetrators and survivors on domestic violence. Journal of Interpersonal Violence, 15, 393-412.

Jenkins, S., \& Baird, S. (2002). Secondary traumatic stress and vicarious trauma: A validation study. Journal of Traumatic Stress, 15, 423-432.

Kassam-Adams, N. (1995). The risks of treating sexual trauma: Stress and secondary trauma in psychotherapists. In B. H. Stamm (Ed.), Secondary traumatic stress: Self-care issues for clinicians, researchers, and educators (pp. 37-50). Lutherville, MD: The Sidran Press.

Marmar, C., Weiss, D., Metzler, T., Delucchi, K., Best, S., \& Wentworth, K. (1999). Longitudinal course and predictors of continuing distress following critical incident exposure in emergency services personnel. Journal of Nervous and Mental Disorders, 187(1), 15-22.

McCann, I. L., \& Pearlman, L. A. (1990). Vicarious traumatization: A framework for understanding the psychological effects of working with victims. Journal of Traumatic Stress, 3(1), 131-149.

Ortlepp, K., \& Friedman, M. (2002). Prevalence and correlates of secondary traumatic stress in workplace lay trauma counselors. Journal of Traumatic Stress, 15, 213-222.

Pearlman, L. (1996). Psychometric review of the TSI Belief Scale, Revision-L. In B. Stamm (Ed.), Measurement of stress, trauma and adaptation (pp. 381-383). Lutherville, MD: Sidran Press.

Pearlman, L., \& MacIan, P. (1995). Vicarious traumatization: An empirical study on the effects of trauma work on trauma therapists. Professional Psychology, Research and Practice, 26, 558-565.

Pearlman, L. A., \& Saakvitne, K. W. (1995). Trauma and the therapist. Countertransference and vicarious traumatization in psychotherapy with incest survivors. New York: W.W. Norton.
Regehr, C., \& Cadell, S. (1999). Secondary trauma in sexual assault crisis work: Implications for therapists and therapy. Canadian Social Work, 1(1), 56-63.

Regehr, C., Chau, S., Leslie, B., \& Howe, P. (2002a). Inquiries into the deaths of children: Impacts on child welfare workers and their organizations. Child and Youth Services Review, 21, 885-902.

Regehr, C., Chau, S., Leslie, B., \& Howe, P. (2002b). An exploration of supervisors \& managers responses to child welfare reform. Administration in Social Work. 26(3) 17-36.

Resnick, H., Kilpatrick, D., Best, C., \& Kramer, T. (1992). Vulnerability-stress factors in development of posttraumatic stress disorder. Journal of Nervous and Mental Disease, 180, 424-430.

Sabin-Farrell, R., \& Turpin, G. (2003). Vicarious traumatization: Implications for the mental health of health workers? Clinical Psychology Review, 23, 449-480.

Schauben, L., \& Frazier, P. (1995). Vicarious trauma: The effects on female counselors of working with sexual violence survivors. Psychology of Women Quarterly, 19, 49-54

Sexton, L. (1999). Vicarious traumatization of counselors and effects on their workplaces. British Journal of Guidance \& Counselling, 27, 393-403.

Talbot, A. (1989). The importance of parallel process in debriefing crisis counselors. Journal of Traumatic Stress, 3, 265-277.

Wall, J. (2001). Trauma and the clinician: Therapeutic implications of clinical work with clients. Clinical Social Work Journal, 29(2), 133-145.

Yassen, J. (1995). Preventing secondary stress disorder. In C. Figley (Ed.), Compassion fatigue: Coping with secondary traumatic stress disorder in those who treat the traumatized (pp. 178-208). New York: Brunner/Mazel.

Zilberg, N., Weiss, D., Horowitz, M. (1982). Impact of event scale: A cross-validation study and some empirical evidence supporting a conceptual model of stress response syndromes. Journal of Consulting and Clinical Psychology, 50, 407-414. 